\title{
Comentarios
}

\section{El Salvador: democracia de baja intensidad}

El objetivo de las presentes reflexiones es caracterizar en su rasgos generales el modelo de transición democrática que mejor describe el caso salvadoreño. Para dicho fin utilizaremos criterios analíticos tomados de la política comparada, rama de importante desarrollo conceptual de la ciencia política empírica contemporánea. La transición democrática salvadoreña, en efecto, a pesar de sus particularidades, comparte algunos elementos comunes con otros procesos de transición democrática en el mundo, a partir de los cuales podemos intentar elaborar una interpretación más rigurosa del desarrollo y de la dinámica de nuestro propio proceso de cambio político. La ocasión, por lo demás, es oportuna ya que con la reciente salida del país de la Misión de Observadores de Naciones Unidas (ONUSAL) virtualmente se ha puesto fin a tres años de difícil instauración democrática.

En los tres últimos años, en efecto, el país vivió un proceso global de cambio político, destinado a transformar el antiguo régimen autoritario en uno democrático. Ello significó la puesta en marcha, de forma simultánea, aunque en cierta medida autónoma, de un doble proceso. Por una parte, un proceso propiamente de desintegración del régimen autoritario y, por otra, un proceso de instauración de las nuevas instituciones democráticas. Al primer caso correspondió un conjunto de esfuerzos por desmilitarizar a la sociedad salvadoreña y desmantelar o rectificar las instituciones ilegítimamente coercitivas, mientras que al segundo proceso, en cambio, correspondió la creación de nuevas y flamantes instituciones y procedimientos destinados a garantizar la vigencia del nuevo ordena- miento democrático.

Estas dos transformaciones han sido plasmadas desde las características particulares del antiguo régimen lo cual, cabe recalcar, ha significado el origen de las principales dificultades experimentadas por el proceso de paz. En El Salvador no se trató de un proceso de redemocratización, dado que el país no disponía previamente de ninguna tradición democrática exitosa. $Y$, por lo tanto, la construcción del nuevo ordenamiento democrático se ha ido desarrollando a lo largo de sus sucesivas fases de manera discontinua, lenta, débil y registrando elevados índices de conflictividad y violencia. Es decir, los cambios pactados en el Acuerdo de Paz han significado una necesaria ruptura respecto de las reglas y estructuras de autoridad del régimen anterior. Tal ruptura, sin embargo, no ha podido lograrse con la velocidad y profundidad que exigen un cambio democrático sólido. Reseñemos brevemente algunas de las causas más claras de este desenlace.

En primer lugar, nos encontramos frente a una transición que no logró escapar a la presencia de fuertes niveles de incertidumbre. Es decir, a pesar de que durante el proceso de negociación las partes crearon un conjunto de mecanismos que darían al proceso estabilidad, credibilidad y agilidad por su dimensión ejecutiva y verificadora - tales como COPAZ y ONUSAL, en la práctica, su funcionamiento no estuvo exento de obstáculos y complicaciones. Ello provocó que, al final, lo conseguido por el proceso fuese mucho menor de lo esperado inicialmente. 
En segundo lugar, el proceso salvadoreño a pesar de haber sido negociado por dos oponentes con similar poder o, al menos, capacidad para neutralizarse mutuamente, terminó a la postre bajo el control de uno solo de ellos. En efecto, el sector gubernamental - subordinado como se encuentra a los intereses de los sectores de derecha- se quedó con el control del proceso de democratización, imponiéndole estrechos límites y cooptando en el camino tanto a la oposición interna como a la misma presencia verificadora internacional. De hecho, el caso salvadoreño ilustra ejemplarmente la máxima que sostiene que "durante la transición, en la medida que existen reglas y procedimientos efectivos éstos suelen estar en manos de los gobernantes autoritarios" (G. O Donnell, P. Schmitter y L. Whitehead (comp), Transiciones desde un gobierno autoritario. Vol. 4 Conclusiones tentativas sobre las democracias inciertas, Buenos Aires, 1988).

En tercer lugar, las fuerzas de oposición no tuvieron capacidad para desempañar un rol realmente constructivo acorde con los desafíos del mismo proceso de transición. El comportamiento del FMLN, en concreto, mostró claramente su fracaso frente al reto crucial de modificar los términos del enfrentamiento político imperante en el país. Esa incapacidad le llevó a adaptarse a los términos de la actual lucha política, que como nos indica el desarrollo del proceso, fue completamente favorable a los sectores e intereses de la derecha. Del FMLN se esperaba, ciertamente, capacidad de liderazgo para conducir el proceso de ejecución de los acuerdos de paz por buen rumbo. Esto es, por la decidida y cabal creación y ampliación de las instituciones y los derechos democráticos. En el camino, sin embargo, cometió errores estratégicos como el aceptar negociar la depuración de la Fuerza Armada y el contenido y las recomendaciones del informe de la Comisión de la verdad. Al hacerlo, pagó un alto precio al dejar virtualmente la conducción del proceso de transición en manos de unos oponentes empeñados en cumplir el mínimo y únicamente de manera formal los compromisos establecidos. Este fracaso de la oposición de izquierda la llevó al final a experimentar un proceso irreversible de división y debilitamiento.
Estos elementos llevan a la siguiente pregunta: ¿puede calificarse de ejemplar y exitoso el proceso de paz en El Salvador? Ambos adjetivos han sido, como sabemos, utilizados con frecuencia por funcionarios internacionales y nacionales al referirse al proceso salvadoreño. No cabe duda que para Naciones Unidas, por ejemplo, el desempeño de su misión en el país constituye un verdadero éxito diplomático que puede mostrar con orgullo a la comunidad internacional. En realidad, en los tres últimos años, el país ha cambiado notablemente. Sin embargo, el proceso no puede calificarse de plenamente ejemplar. Al menos no en el sentido de constituirse como un modelo de cambio político. Cada proceso de transición, en efecto, resulta ser una experiencia única que, si bien comparte rasgos comunes con otros procesos similares, éstos deben ser cuidadosamente integrados en su estudio e interpretación. Tampoco se trata de una experiencia completamente exitosa. Los importantes logros del proceso han marcado, en efecto, su irreversabilidad. Una consideración rigurosa y detallada muestra, no obstante, sus puntos problemáticos y débiles. Por ejemplo, el proceso de reconciliación nacional junto con el de desmilitarización, a pesar de los innegables avances registrados, muestran déficit y limitaciones en su implementación al tiempo que las estructuras judiciales del país continúan siendo débiles e ineficientes. Lo anterior queda más claro al caracterizar con detalle el proceso global de cambio político en El Salvador.

La transición a la democracia en el país puede caracterizarse o calificarse, en efecto, como una transición de baja intensidad. Por ella entendemos al proceso que maneja niveles parciales, débiles, exclusivos y conflictivos de democratización (C. Cansino y V. Alarcón, América Latina: ¿renacimiento o decadencia?, San José, 1994). Por lo tanto, se trata de una transición democrática con altos niveles de incertidumbre para su consolidación y que, en consecuencia, se encuentra seriamente amenazada por una regresión autoritaria. Debe aclararse que, en el caso salvadoreño, ello no significa, por supuesto, un retorno a la confrontación militar, pero sí el peligro de fracasar en la consolidación de la democracia. Es decir, con una transi- 
ción de baja intensidad es más factible la configuración de un autoritarismo de nuevo tipo que permita mayores márgenes de liberalización, pero donde las estructuras de autoridad, las normas y los valores -componentes básicos de todo régimen político- continúen obedeciendo, en definitiva, a los patrones autoritarios. Caracterizaremos, entonces, la transición democrática en El Salvador a la luz de los criterios que nos ofrece la teoría del cambio político.

Tenemos, por tanto, que una transición democrática es sectorial o parcial cuando sólo alguno o algunos - pero no todos- los componentes del régimen han logrado autonomía y legitimidad. En este sentido, en un proceso de instauración democrática completamente exitoso, tanto los partidos políticos como los diversos grupos de interés, al igual que las diversas instituciones del régimen, deben adquirir sus propios intereses así como crear o activar mecanismos fuertes de autorreforzamiento y reproducción, condiciones que se han logrado sólo parcialmente en el caso salvadoreño. De hecho, el proceso de ejecución del Acuerdo de Paz no ha dado paso a una afirmación amplia de los distintos componentes de una régimen democrático. Los fallidos intentos por reformar el poder judicial, las dificultades para darle credibilidad al juego de partidos, las limitadas reformas en materia electoral, Jos innumerables obstáculos enfrentados y el relativamente lento despliegue de la nueva Policía Nacional Civil y, ante todo, la incompleta desmilitarización de la sociedad salvadoreña son indicadores objetivos de la construcción parcial de estructuras eficaces de convivencia democrática.

La teoría del cambio político asegura, en segundo lugar, que una transición democrática es débil o fuerte dependiendo del grado de legitimidad que muestran los distintos componentes del nuevo ordenamiento institucional. $\mathrm{Y}$, como hemos experimentado en el caso salvadoreño, la instauración es débil, ya que el conjunto de actitudes positivas de apoyo alcanzado por las nuevas instituciones democráticas es débil.

Nuestra transición también puede, en tercer lugar, calificarse de exclusiva. Este criterio se refiere al grado de participación y consolidación de las

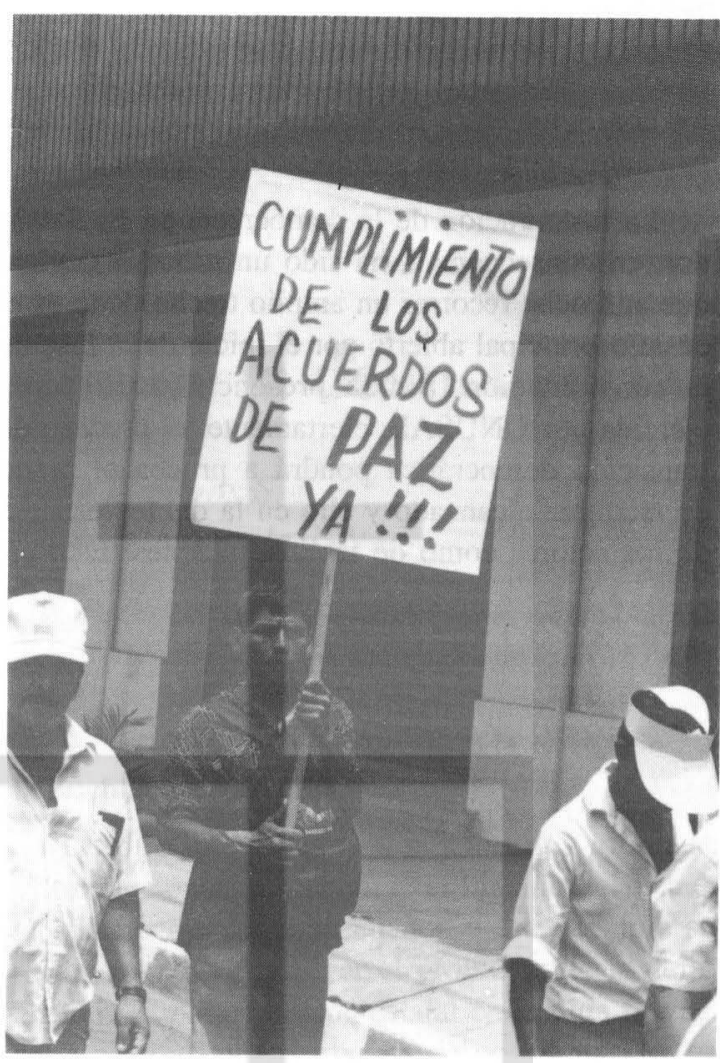

estructuras de intermediación (partidos políticos) y su relación con los grupos de interés (sindicatos, organizaciones no gubernamentales, etc.) durante la transición. El sistema de partidos salvadoreños se caracteriza en la presente coyuntura por su elevado nivel de conflictividad interna, por una importante erosión de su clientela electoral y por una grave crisis de identificación ideológica. Pero más negativo aún, es su incapacidad para representar y canalizar" las demandas de los diferentes sectores de la sociedad civil salvadoreña. Es decir, nuestros partidos políticos no cumplen con una de las funciones clásicas y cruciales de todo partido, consistente en desempeñar un rol de protección hacia los grupos de interés. Por ello, en lo que se refiere a los partidos políticos, la transición es exclusiva.

Finalmente, decimos que tenemos una transición democrática conflictiva porque dicho proceso ha mostrado rasgos característicos que así lo indican. Por ejemplo, las decisiones han sido, de manera general, tomadas por el gobierno sin el apoyo de la oposición, existe todavía una fuerte 
polarización ideológica entre el gobierno y la oposición y, ante todo, hemos sido testigos de cómo los conflictos entre los actores políticos y sociales han sido y continúan siendo sumamente intensos.

La instauración de la democracia en El Salvador, en consecuencia, ha sido un proceso gradual que aún debe recorrer un amplio trecho. Este es el desafío principal abierto por el inicio de la fase de la consolidación. Sin la presencia verificadora ejercida por ONUSAL, ciertamente, el proceso de transición democrática pondrá a prueba el grado de madurez alcanzado y ello en la doble vertiente de los actores como de las instituciones. Esto es, las nuevas instituciones establecidas por los acuerdos de paz enfrentan ahora el desafío de mantenerse y afirmarse en el tiempo de forma viable y persistente. Tal dinámica es la que, en definitiva, posibilitará a los actores políticos las condiciones para su participación; dará paso, asimismo, a un régimen en donde existirá la tolerancia a la oposición y, finalmente, reglamentará adecuada y eficazmente la competencia y el ejercicio de los corespondientes derechos políticos de todos los ciudadanos.

A. $\mathbf{S}$. 